\title{
Coupled Land-Atmosphere Intraseasonal Variability of the West African Monsoon in a GCM
}

\author{
SALLY L. LAVENDER* \\ School of Environmental Sciences, University of East Anglia, Norwich, United Kingdom \\ CHRISTOPHER M. TAYLOR \\ Centre for Ecology and Hydrology, Wallingford, United Kingdom \\ ADRIAN J. MATTHEWS \\ School of Environmental Sciences and School of Mathematics, University of \\ East Anglia, Norwich, United Kingdom
}

(Manuscript received 8 September 2009, in final form 25 March 2010)

\begin{abstract}
Recent observational studies have suggested a role for soil moisture and land-atmosphere coupling in the 15-day westward-propagating mode of intraseasonal variability in the West African monsoon. This hypothesis is investigated with a set of three atmospheric general circulation model experiments. 1) When soil moisture is fully coupled with the atmospheric model, the 15-day mode of land-atmosphere variability is clearly identified. Precipitation anomalies lead soil moisture anomalies by 1-2 days, similar to the results from satellite observations. 2) To assess whether soil moisture is merely a passive response to the precipitation, or an active participant in this mode, the atmospheric model is forced with a 15-day westward-propagating cycle of regional soil moisture anomalies based on the fully coupled mode. Through a reduced surface sensible heat flux, the imposed wet soil anomalies induce negative low-level temperature anomalies and increased pressure (a cool high). An anticyclonic circulation then develops around the region of wet soil, enhancing northward moisture advection and precipitation to the west. Hence, in a coupled framework, this soil moisture-forced precipitation response would provide a self-consistent positive feedback on the westward-propagating soil moisture anomaly and implies an active role for soil moisture. 3) In a final sensitivity experiment, soil moisture is again externally prescribed but with all intraseasonal fluctuations suppressed. In the absence of soil moisture variability there are still pronounced surface sensible heat flux variations, likely due to cloud changes, and the 15-day westward-propagating precipitation signal is still present. However, it is not as coherent as in the previous experiments when interaction with soil moisture was permitted. Further examination of the soil moisture forcing experiment in GCM experiment 2 shows that this precipitation mode becomes phase locked to the imposed soil moisture anomalies. Hence, the 15-day westward-propagating mode in the West African monsoon can exist independently of soil moisture; however, soil moisture and land-atmosphere coupling act to feed back on the atmosphere and further enhance and organize it.
\end{abstract}

\section{Introduction}

The West African region receives almost all its annual rainfall during the monsoon season. The West African

* Current affiliation: University of Melbourne, Parkville, Victoria, Australia.

Corresponding author address: Sally L. Lavender, School of Earth Sciences, University of Melbourne, Parkville VIC 3010, Australia. E-mail: sallyl@unimelb.edu.au monsoon (WAM) is highly variable on decadal, annual, and intraseasonal time scales (Lebel et al. 2000). There are a number of external and internal forcings on this monsoon system including sea surface temperature (SST; Folland et al. 1986; Rowell et al. 1995; Janicot et al. 1998), land-atmosphere feedbacks (Taylor et al. 1997; Grodsky and Carton 2001; Douville 2002), and large-scale circulation features (Matthews 2004; Mounier et al. 2008; Lavender and Matthews 2009).

On the intraseasonal time scale, there are prolonged wet and dry events during the monsoon season (Janicot 
and Sultan 2001) that can be devastating to crop yields in a region that has a history of droughts and famine. Hence, there has been considerable interest in the intraseasonal variability of the WAM during recent years. Janicot and Sultan (2001) found large variations in rainfall and wind field data during the WAM within two frequency bands: one with a period of around 15 days and the other within the 25-60-day band. The longer-scale (25-60 days) variability is now thought to be associated with the MaddenJulian oscillation (MJO; Matthews 2004; Lavender and Matthews 2009) and intraseasonal variability of the Asian summer monsoon (Janicot et al. 2009).

Mounier and Janicot (2004) found there are two independent modes of convection in the 10-25-day period. The first mode is associated with a zonal dipole of convection between Africa and the western Atlantic that modulates the advection of moisture from the Atlantic into Africa (the "Guinean" mode). The second mode is a westwardpropagating signal, consistent with the "Sahelian" mode found by Sultan et al. (2003). In the Sahelian mode, 15-day period of variability, enhanced rainfall anomalies are associated with a more cyclonic circulation over the Sahara, controlling a southward pressure gradient and a northward advection of moisture over West Africa, thus enhancing the monsoon winds (Janicot and Sultan 2001; Sultan et al. 2003).

In semiarid regions such as the Sahel, there are strong interactions between soil moisture and the atmosphere by evaporation (Koster et al. 2004). The availability of soil moisture has a strong effect on the partitioning of incoming radiative energy into sensible and latent heat fluxes. These may then influence the planetary boundary layer and the development of precipitating systems (e.g., Betts and Ball 1998). However, accurate measurements of surface fluxes are difficult to obtain because of variations in cloudiness, precipitation, and vegetation properties. Taylor (2008) reexamined the Sahelian mode using satellite passive microwave data sensitive to soil moisture. Significant variations in soil moisture and associated sensible heat fluxes on the 15-day time scale were found, consistent with a feedback on the low-level vorticity structure that produces the initial variability in rainfall. The need for climate simulations to complement this diagnostic study and to give a more detailed understanding of the soil moisture-atmosphere coupling is emphasized.

This paper builds on the work of Taylor (2008) and aims to examine the effect of regional soil moisture anomalies on the WAM. Simulations with a GCM are used to address the following questions. First, how well can a GCM represent this intraseasonal variability in soil moisture? Second, if the model is forced with prescribed soil moisture variability, how does this feed back on the atmospheric dynamics and rainfall? Last, if soil moisture variability is artificially suppressed in the model, what effect does it have on the simulated atmospheric variability? Analysis of this suite of GCM simulations will allow us to determine whether soil moisture is fully coupled and feeds back to the atmosphere (and hence rainfall) or whether it is just a passive response to the precipitation forcing.

The following section describes the satellite data and model used. Intraseasonal variability of soil moisture from satellite and model data is examined in section 3. Details of the soil moisture sensitivity experiments and the results are analyzed in sections 4 and 5, respectively. Last, conclusions are presented in section 6 .

\section{Data and model}

\section{a. AMSR-E soil moisture data}

Soil moisture data based on observations from the Advanced Microwave Scanning Radiometer for Earth Observing System (AMSR-E) on board the Aqua satellite were obtained for the period July 2002-December 2009 from the Atmospheric Data Access for the Geospatial User Community (ADAGUC) project (Owe et al. 2008). The estimates of soil moisture are derived according to the Land Surface Parameter Model (LPRM; Owe et al. 2008) from measurements of brightness temperature at 6.9 and $10.7 \mathrm{GHz}$, which are directly sensitive only to the top $1 \mathrm{~cm}$ of soil. Furthermore, the soil moisture signal is suppressed in areas of significant vegetation cover. While this is not a problem in the Sahel, it will influence data south of $10^{\circ} \mathrm{N}$. The soil moisture retrievals are derived from a sun-synchronous satellite platform, resulting in descending orbits crossing the equator at approximately 1:30 a.m. solar time and ascending orbits at 1:30 p.m. solar time. Gruhier et al. (2010) compared five different satellite-based soil moisture products with in situ soil moisture from a site in Mali, West Africa. In terms of soil moisture retrieval, the AMSR-E product used in this study was found to have a better correlation with ground station measurements than the other products analyzed. Although AMSR-E soil moisture values are slightly overestimated compared to ground measurements, large soil moisture increases associated with strong precipitation events during the monsoon season are well captured in the AMSR-E product. Thus, while the absolute accuracy of the product may be questionable, the space-time variability in soil moisture associated with wet and dry spells will be represented in the dataset. In the current study, data from both ascending and descending overpasses were used to construct daily maps of soil moisture, on a $0.25^{\circ}$ grid. In locations where both overpasses produced data on a particular day, the average of the two values was taken. 


\section{b. The $U M$}

The model used in this study is the Met Office Unified Model (UM), so called because it is designed to be run as a global, regional, and mesoscale model for forecasting and climate simulations. Version 4.5 uses a hydrostatic set of dynamical equations on a vertical hybrid sigma/ pressure coordinate system and a regular latitudelongitude grid in the horizontal (Cullen 1993). The Hadley Centre atmosphere-only model, version 3, HadAM3, is run here, with 30 vertical levels (corresponding to a layer thickness of approximately $50 \mathrm{hPa}$ in the midtroposphere) and a horizontal grid of $3.75^{\circ}$ longitude $\times 2.5^{\circ}$ latitude. The atmosphere is coupled to the Met Office Surface Exchange Scheme, version 2.2 (MOSES 2.2; Essery et al. 2001). This version of MOSES includes a tiled representation of the land surface. Surface fluxes and temperature are calculated on nine tiles, each representative of a different cover type, and weighted by their tile fractional coverage to produce gridbox mean values. An error in the calculation of the soil hydraulic parameters used in earlier studies (Dharssi et al. 2009) has been corrected in these simulations.

The model was run for 23 years, from 1 January 1983 to 31 December 2005. The model was forced with 90-day low-pass-filtered SSTs from the National Oceanic and Atmospheric Administration (NOAA) optimum interpolation version 2 (OI.v2) SST analysis dataset (Reynolds et al. 2002). These SSTs will still contain interannual variability but will not have any coherent forcing on the intraseasonal scale.

\section{Intraseasonal variability in soil moisture}

The dominant modes of intraseasonal variability on the 10-25-day time scale in the satellite-derived soil moisture are now examined, and the ability of the model to capture these is assessed. To obtain the intraseasonal anomalies, the first five harmonics of the annual cycle were removed from each dataset.

\section{a. AMSR-E soil moisture}

Previous work has shown variability in the WAM on two time scales: one with a period of around 15 days and the other within the 25-60-day band. Here, we perform a spectral analysis on AMSR-E soil moisture anomalies over the West African monsoon region. A time series of daily, area-averaged $\left(12.5^{\circ}-17.5^{\circ} \mathrm{N}, 20^{\circ} \mathrm{W}-30^{\circ} \mathrm{E}\right)$ soil moisture was computed for each of the seven June-September monsoon seasons from 2003 to 2009. The sample spectrum was then calculated for each 122-day season. The mean of these $n=7$ spectra is shown in Fig. 1. To test for the statistical significance of peaks in this power spectrum, the null hypothesis is that the underlying

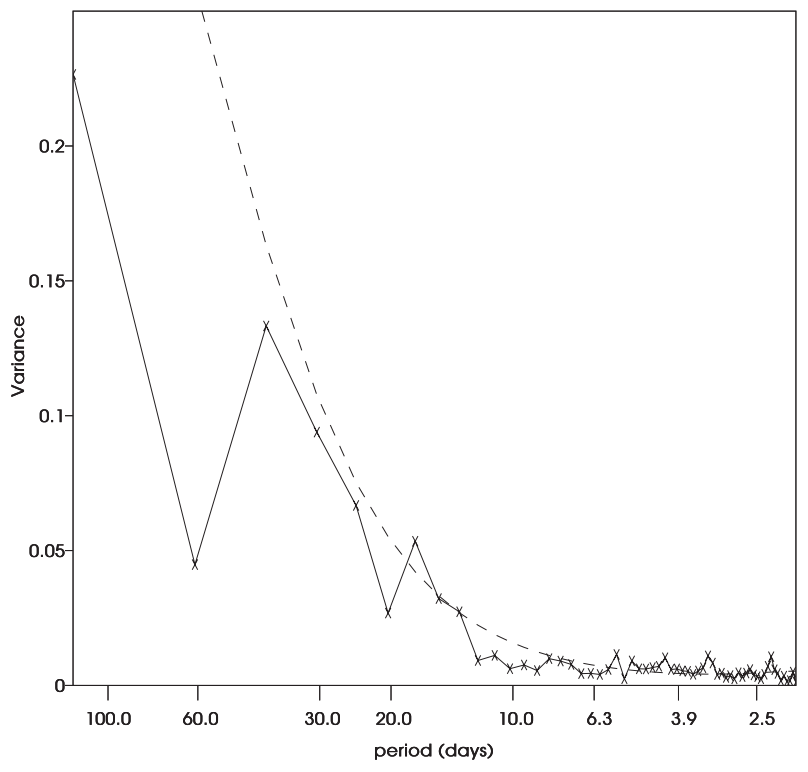

FIG. 1. Power spectrum of area-averaged $\left(12.5^{\circ}-17.5^{\circ} \mathrm{N}, 20^{\circ} \mathrm{W}-\right.$ $\left.30^{\circ} \mathrm{E}\right)$ satellite soil moisture anomalies: mean of the individual power spectra from the seven June-September seasons (2003-09). The $90 \%$ confidence limit is shown by the dashed line.

distribution is a random first-order Markov process. The theoretical power spectrum of such a process can be calculated from the lag-1 autocorrelation coefficient of the data $(\mathrm{r} 1=0.87)$. The variance of each spectral estimate then follows a chi-squared distribution with $2 n=14$ degrees of freedom (Wilks 1995). The dashed line in Fig. 1 shows the $90 \%$ significance level based on these calculations. The largest contribution to the total variance occurs in the seasonal peak $(23 \%)$, with a peak at around 45 days $(14 \%)$ and a significant peak at 18 days $(6 \%)$. These correspond well with those found in precipitation by Sultan et al. (2003). The 30-60-day band accounts for approximately $35 \%$ of the total variance, while the 10 25 -day band accounts for approximately $20 \%$. The variability of soil moisture within this 10-25-day band found both here and in previous research using precipitation data (e.g., Sultan et al. 2003; Mounier and Janicot 2004) will now be analyzed in more detail.

An empirical orthogonal function (EOF) analysis of the 10-25-day-filtered satellite intraseasonal soil moisture anomalies during the 2003-09 months of JuneSeptember - that is, the monsoon season - was performed on a domain over West Africa. This domain covers longitudes from $20^{\circ} \mathrm{W}$ to $30^{\circ} \mathrm{E}$ and latitudes from $5^{\circ}$ to $20^{\circ} \mathrm{N}$. The leading two eigenvectors (EOF1 and EOF2) account for $14 \%$ and $9 \%$ of the filtered variance, respectively (3\% and $2 \%$ of the total variance at all time scales, respectively). According to the criteria of North et al. (1982), they are both significantly separated from each other and from 

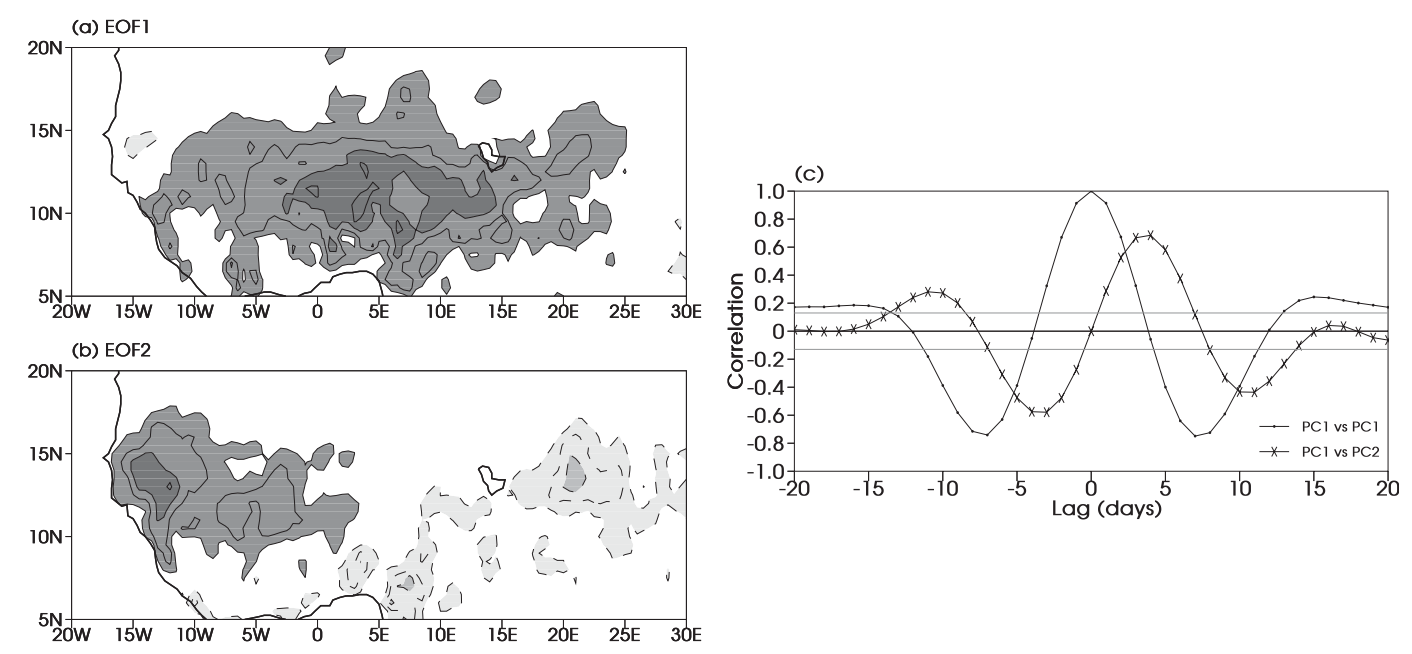

FIG. 2. (a) EOF1 and (b) EOF2 of 10-25-day-filtered satellite soil moisture over the Sahel $\left(5^{\circ}-20^{\circ} \mathrm{N}, 20^{\circ} \mathrm{W}-30^{\circ} \mathrm{E}\right)$ for June-September of 2003-09. Contour interval is $0.3 \mathrm{~kg} \mathrm{~m}^{-3}$, and negative contours are dashed. Shading is shown by the legend. (c) Lag correlations of PC1 against PC1 and the PC2 against PC1 time series from the 10-25-dayfiltered AMSR-E analysis, June-September of 2003-09 over the Sahel. The horizontal axis shows the lag in days; the vertical axis shows the correlation coefficient. The gray lines indicate the $95 \%$ significance level.

the remaining eigenvectors; hence, the mixing of variance between eigenvectors by sampling is not an issue. The dominant mode of variability (EOF1; Fig. 2a) is a large region of positive soil moisture across the majority of the Sahel. The second EOF (Fig. 2b) shows positive anomalies extending from around $0^{\circ} \mathrm{E}$ to the western coast at a latitude of around $12.5^{\circ} \mathrm{N}$ and negative anomalies southeast of these, extending to $30^{\circ} \mathrm{E}$.

Time-lagged correlations between the principal component (PC) time series (which describe the temporal evolution of their respective EOF spatial structure) were calculated (Fig. 2c). The critical correlation coefficient at the $95 \%$ level $\left(r_{95}\right)$ was calculated as described by Livezey and Chen (1983). There were 7 years of data and 122 days in a season, giving $7 \times 122=854$ data samples. The decorrelation time was taken as the lag at which the autocorrelation function (PC1 lagged with respect to itself) first crosses zero-in this case, 4 days (Fig. 2c). Hence, there were 854/4 $=214$ degrees of freedom and $r_{95}=$ 0.13 . The lagged correlation of $\mathrm{PC} 1$ with respect to itself shows a periodicity of between 15 and 20 days. The first two PCs are significantly correlated, with PC2 lagging PC1 by 4 days. Together with the spatial structures of EOF1 and EOF2, this describes a westward-propagating structure, consistent with the previous studies of the 1025-day variability over the West African monsoon described in section 1 .

Time-lagged composites of filtered satellite soil moisture were calculated. The day 0 composite (Fig. 3e) is the mean of the anomaly maps on days when PC1 of soil moisture was a maximum and above a threshold of one standard deviation (37 cases). The day -8 composite, for example, is the mean of the 37 anomaly maps that occurred 8 days previously to the 37 day 0 maps (Fig. 3a). Statistical significance was calculated using a Student's $t$ test. When the analysis was repeated with unfiltered data, the composites were qualitatively similar but noisier. These patterns resemble those found by Taylor (2008, his Fig. 7) using a different approach and based on passive microwave data from a different satellite. Day -8 (Fig. 3a) has a similar spatial pattern of anomalies as EOF1 (Fig. 2a) but with the opposite sign. There is a large region of negative soil moisture anomalies over the Sahelian region with a small positive region over the western coast and east of $35^{\circ} \mathrm{E}$. Over the following days, negative anomalies occur farther west, while positive anomalies advance from the east. Between days 0 and 8 (Figs. 3e-h), the sequence is repeated, with positive soil moisture values propagating toward the west coast. The westward propagation of soil moisture found here is consistent with previous analyses of rainfall (Janicot and Sultan 2001; Sultan et al. 2003).

\section{b. Model soil moisture}

The 10-25-day variability in the top-level soil moisture is now investigated using a fully coupled landatmosphere model in which the soil moisture is allowed to vary freely with time. This will be compared with the satellite data to examine how well the model captures the variability. The coupling of soil moisture to atmospheric variables within the model is also analyzed.

An EOF analysis of the intraseasonal 10-25-dayfiltered modeled soil moisture data (from the top level, $0-0.1 \mathrm{~m}$ ) was performed over the West African domain 
(a) Day -8

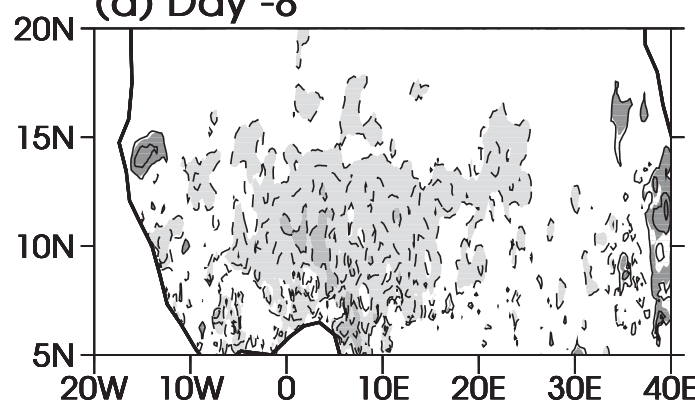

(b) Day -6
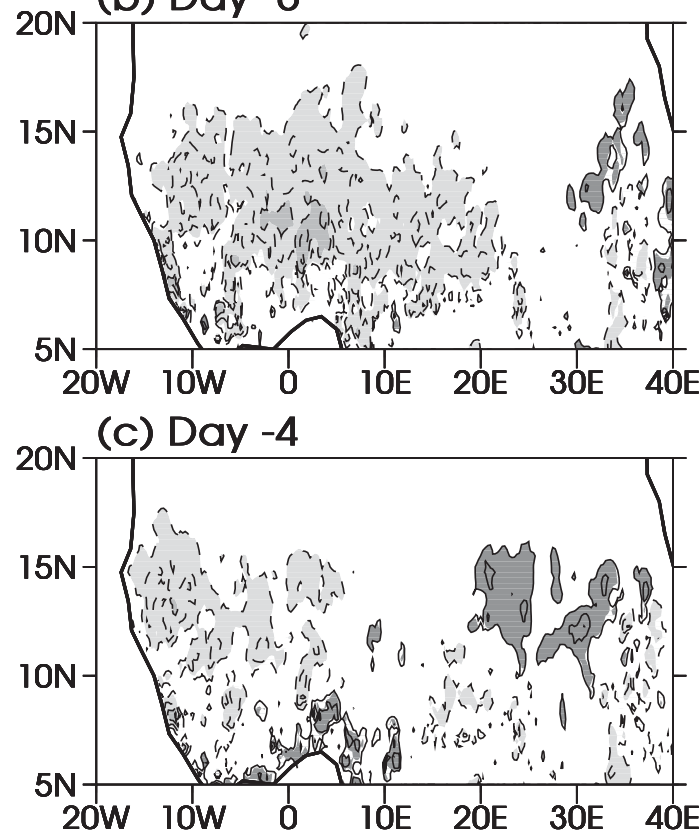

(d) Day -2
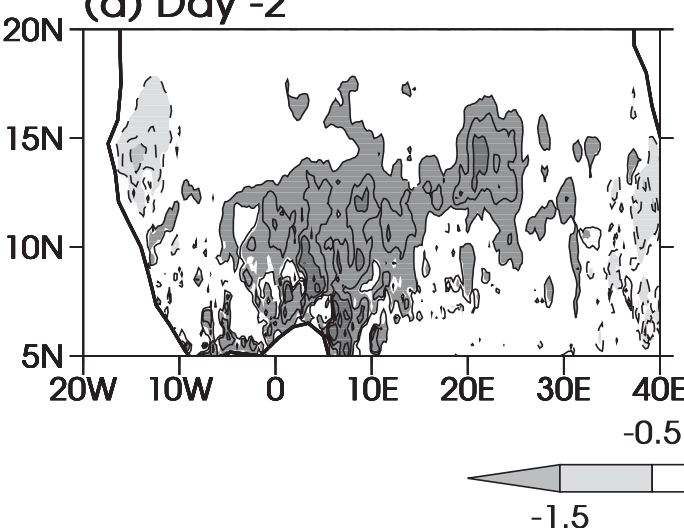

$20 \mathrm{~N}$ (e) Day 0

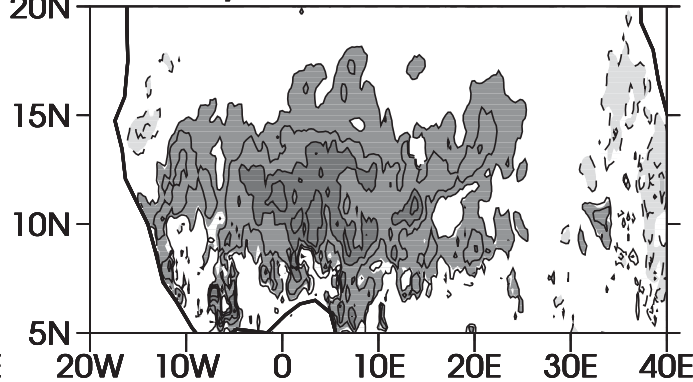

(f) Day 2

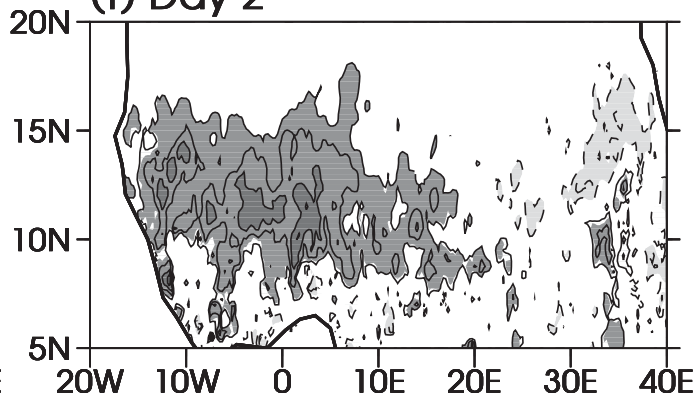

(g) Day 4

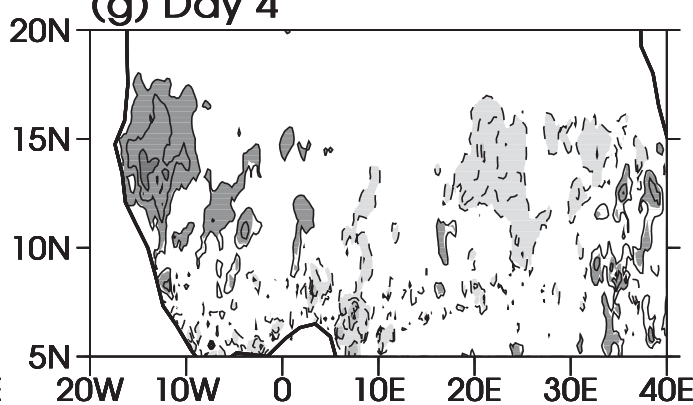

(h) Day 6

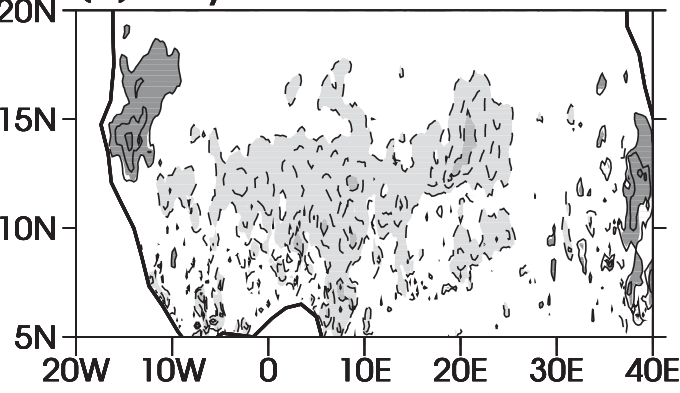

1.5

FIG. 3. Lagged composites of filtered satellite soil moisture anomalies based on PC1 of 10-25-day-filtered soil moisture, June-September of 2003-09 on days (a) -8 to (h) 6 . Contour interval is $0.5 \mathrm{~kg} \mathrm{~m}^{-3}$, and negative contours are dashed. Shading is shown by the legend; only values significant at the $95 \%$ level are shaded.

$\left(5^{\circ}-20^{\circ} \mathrm{N}, 20^{\circ} \mathrm{W}-30^{\circ} \mathrm{E}\right)$ for the June-September seasons of 1983-2005. The leading two eigenvectors accounted for $23 \%$ and $13 \%$ of the variance $(3.5 \%$ and $2 \%$ of the total variance at all time scales), respectively, and were well separated from each other and the remaining eigenvectors (North et al. 1982). The spatial structures of the model EOFs were very similar to those from the observations (not shown), and the model reproduces 
the main spatial patterns of observed intraseasonal soil moisture variability well.

The percentage variance explained in the model may be larger than in the observations for several reasons, even if the model did simulate the soil moisture perfectly. The satellite only detects soil moisture in the top centimeter, typically once per day at a fixed time of day, and the signal is therefore rather sensitive to the time since rainfall in the hours after an event. In contrast, the model soil moisture is a time mean rather than a snapshot and represents a top soil layer of $10-\mathrm{cm}$ depth. Furthermore, there are inherent errors in the retrieval of soil moisture from satellite (Gruhier et al. 2010) that reduce the signal-to-noise ratio relative to the model. The observed data are also on a much finer grid, which will contain small-scale variability not represented in the model, thus decreasing the percentage of variance accounted for by the leading EOFs. Quantitative comparisons of the amplitude between the satellite and modeled data therefore cannot be made. On the other hand, the periodicity and propagation speed can be directly compared. The time-lagged composites from the model will now be evaluated.

Time-lagged composites are produced with unfiltered soil moisture data based on when PC1 of the modeled analysis is a maximum (Fig. 4) and above a threshold of one standard deviation (90 cases). These composites show a similar pattern of a westward-moving signal in soil moisture as the satellite data (Fig. 3). Day -8 (Fig. 4a) has a large region of negative anomalies to the east of $0^{\circ} \mathrm{E}$. These anomalies strengthen and propagate westward by day -6 (Fig. 4b). Consistent with Fig. 3c, day -4 (Fig. 4c) shows a region of positive anomalies at $20^{\circ} \mathrm{E}$. These extend westward over the following days, and the region of negative anomalies in the west continue to propagate westward. By day 0 (Fig. $4 \mathrm{e}$ ), there is the similar pattern as day -8 (Fig. 4 a) but with the opposite sign. The model captures the observed large-scale pattern of soil moisture anomalies, for example, the positive soil moisture anomaly shifting westward from $20^{\circ} \mathrm{E}$ on day -4 to $10^{\circ} \mathrm{W}$ on day 4 (Figs. 3 and 4 ). The largescale features of intraseasonal variability in soil moisture on the 10-25-day time scale is therefore well represented by this atmospheric GCM.

We will now use the model to examine the evolution of the surface fluxes and their relationships with the land and lower atmosphere. Composite time series of variables are computed based on when PC1 of soil moisture is maximized (Fig. 5). Precipitation anomalies are found to lead top-level soil moisture anomalies by approximately 1-2 days (Fig. 5a). Variations in cloud cover associated with this precipitation signal produce a minimum in incoming shortwave radiation, which leads the maximum soil moisture by 1 day (Fig. 5b). The time series of sensible and latent heat fluxes are driven by a combination of incoming radiation (controlling the total flux) and soil moisture (altering the partition between sensible and latent heat). Sensible heat flux is minimum when soil moisture is a maximum, while the maximum in latent heat lags soil moisture by approximately two days. In Fig. 5c, boundary layer temperatures are negatively correlated with soil moisture and affect the mean sea level pressure, which lags soil moisture by 1 day. This relationship between soil moisture, sensible heat flux, and atmospheric temperature is consistent with the surface feedback of Taylor (2008). Rainfall moistens the surface, which in turn cools the lower atmosphere, leading to an increase in surface pressure. In the next section, additional simulations of the GCM that isolate the role of surface hydrology on the atmospheric structure and attempt to diagnose the two-way coupling between the soil moisture field and ultimately the precipitation are described.

\section{Soil moisture sensitivity experiments}

\section{a. Introduction}

Two soil moisture sensitivity simulations (a "control" and a "perturbation" run) that investigate how soil moisture influences the variability of the WAM are now described. These differ from the coupled run described in the previous section only in the representation of the surface hydrology. The control and perturbation runs have altered land boundary conditions, such that the prognostic equations for soil moisture are bypassed and the evolution of soil moisture is prescribed. In addition, evaporation of intercepted rainfall on the vegetation canopy is switched off.

We wish to assess the effect of soil moisture availability on the atmosphere via sensible and latent heat fluxes. We assume that at the scale of the model grid box, variations in soil moisture rather than soil type determine these fluxes during the wet season. In the UM MOSES 2.2 land surface scheme, soil moisture affects the surface fluxes through both a stomatal and a bare soil evaporative resistance (Essery et al. 2001). The total evaporative resistance is dominated by the stomatal term when vegetation predominates, while in the Sahel and Sahara, it is the bare soil resistance that primarily controls the partition between sensible and latent heat fluxes. The bare soil resistance $r_{\text {soil }}\left[\mathrm{s} \mathrm{m}^{-1}\right.$; Eq. (1)] is computed as

$$
r_{\text {soil }}=\frac{100}{\left(\frac{\theta_{1}}{\theta_{c}}\right)^{2}},
$$


(a) Day -8

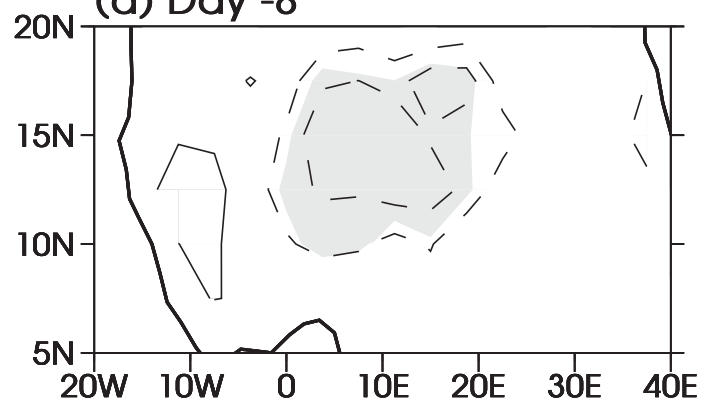

(b) Day -6
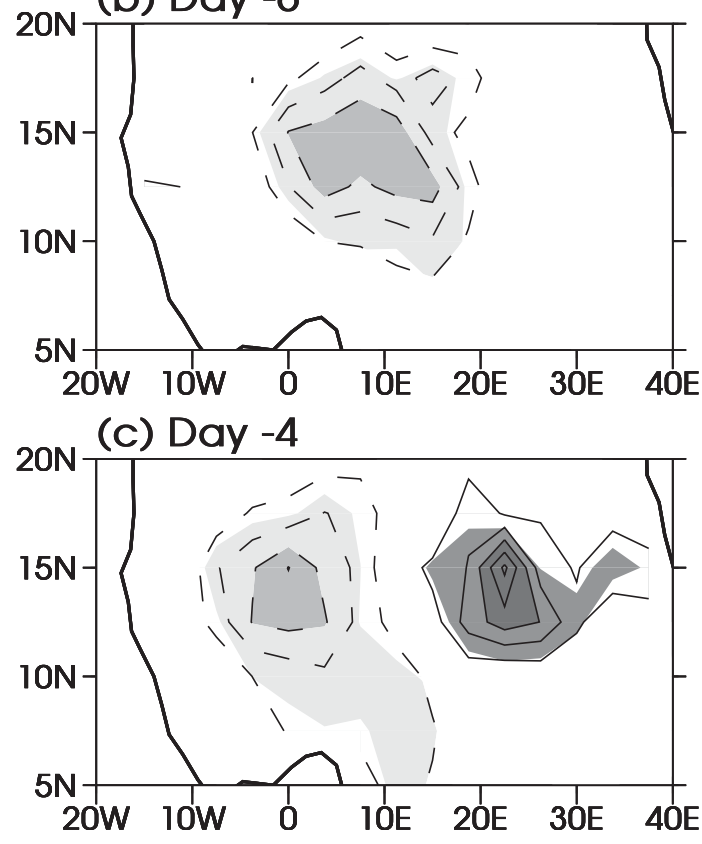

(d) Day -2

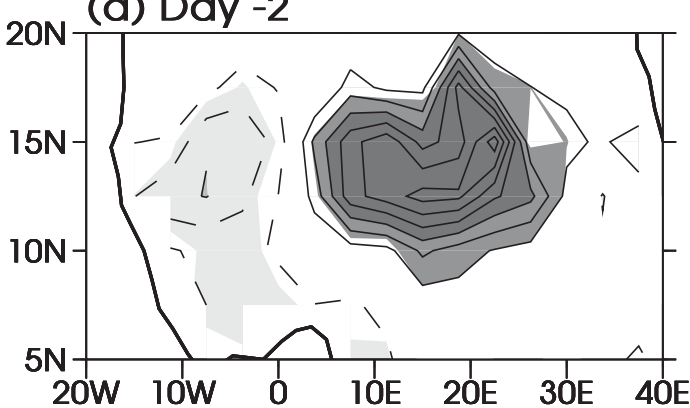

20W IOW 0 IOE 20E 30E 40E

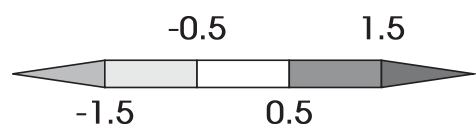

FIG. 4. As in Fig. 3, but for unfiltered modeled (top level) soil moisture anomalies based on PC1 of 10-25-day-filtered soil moisture from the coupled run; see Table 1 for summary of model integrations.

where $\theta_{1}$ is the volumetric water content of the top soil level $(0-10 \mathrm{~cm})$ and $\theta_{c}$ is the volumetric water content at the critical point, a texture-dependent property of the soil. Imposing a uniform value of $\theta_{1}$ across the domain does not produce constant values of $r_{\text {soil }}$ because of (e) Day 0

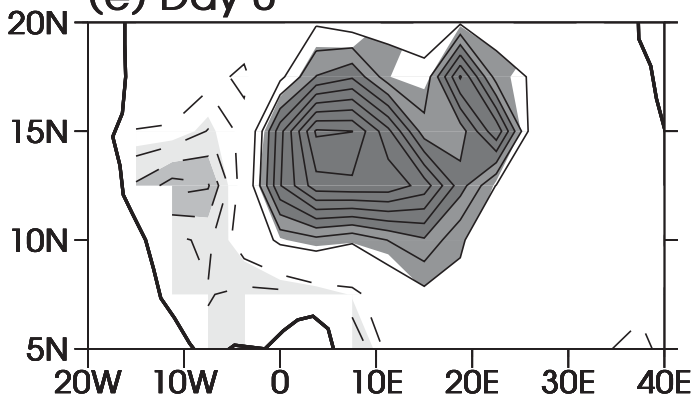

(f) Day 2
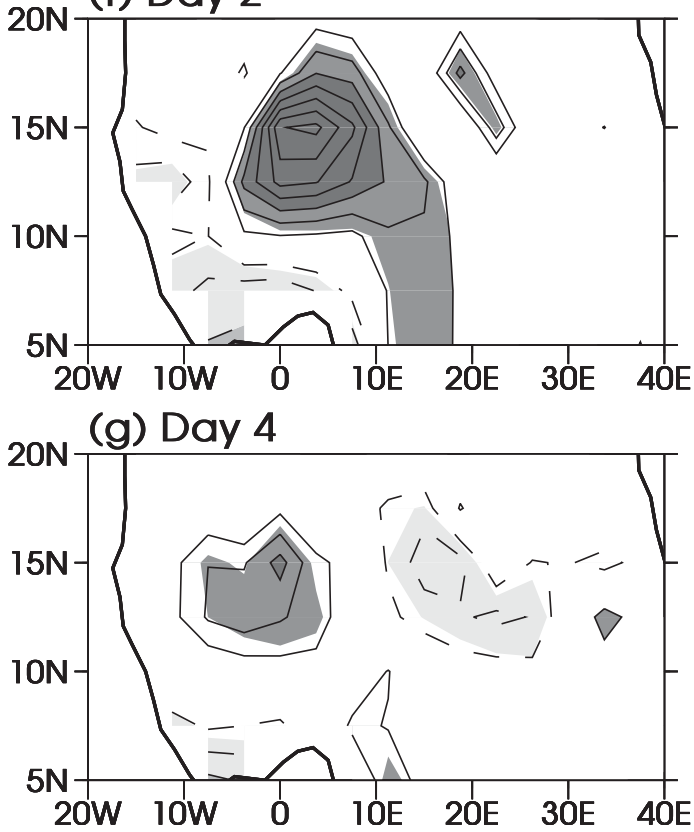

$20 \mathrm{~N}$ (h) Day 6

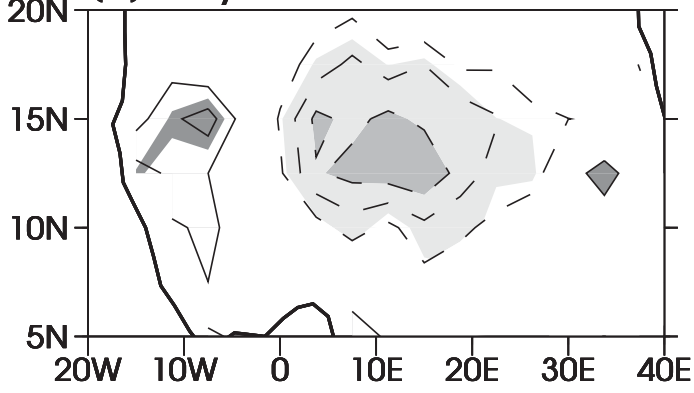

1.5 geographical variations in soil texture (and hence $\theta_{c}$ ), as inferred from the Food and Agriculture Organization (FAO) global soil map, though the accuracy of the resulting map of $\theta_{c}$ is questionable. To impose simple boundary conditions on the model that are qualitatively 
(a)

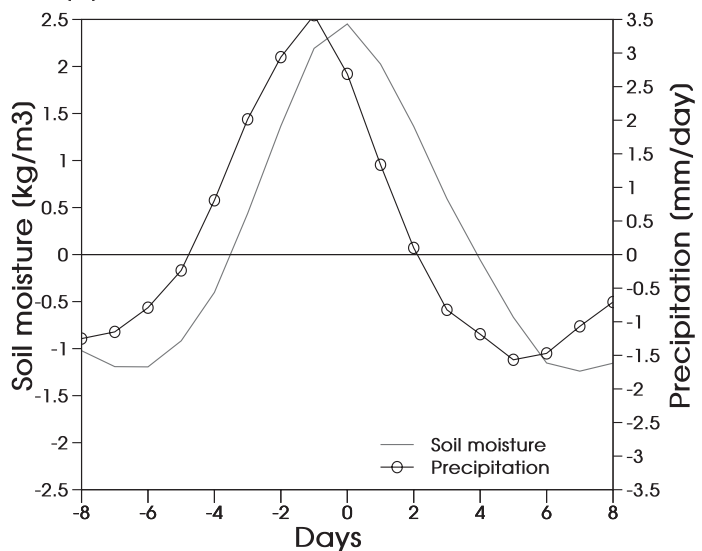

(b)

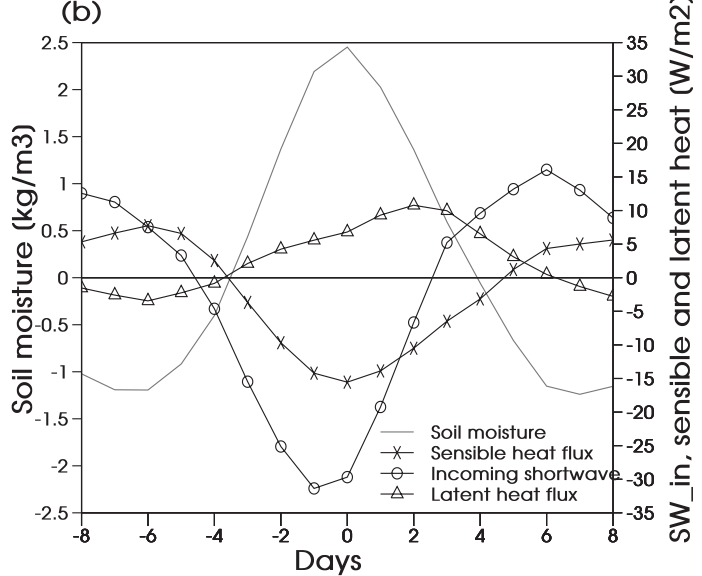

(c)

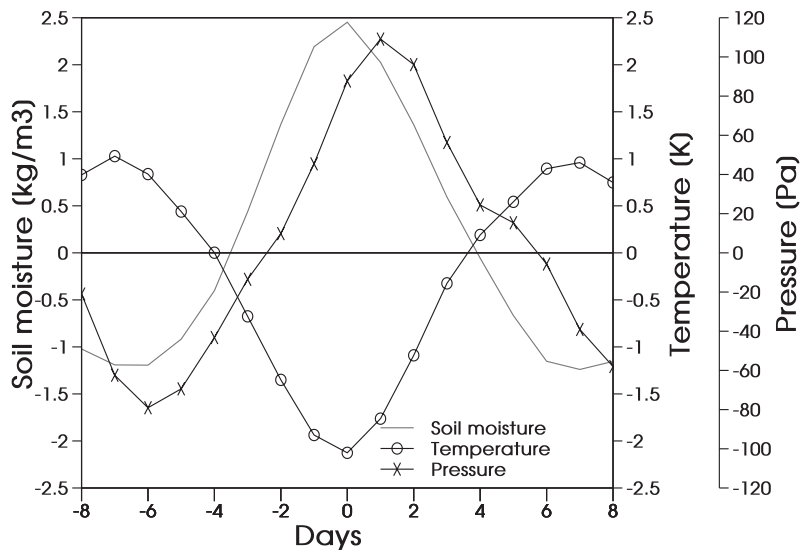

FIG. 5. Lagged composites of unfiltered atmospheric variables, averaged between $12.5^{\circ}$ and $17.5^{\circ} \mathrm{N}$ and $0^{\circ}$ and $20^{\circ} \mathrm{E}$, and lagged with respect to soil moisture from the coupled run. (a) Precipitation; (b) incoming shortwave radiation, sensible heat flux, and latent heat flux; (c) temperature at $925 \mathrm{hPa}$ and mean sea level pressure. A legend is included on each plot.

consistent with the satellite data, we choose instead to impose variations in $r_{\text {soil }}$ and then back-calculate the required values of $\theta_{1}$ and hence soil moisture, for ingestion by the model.

\section{b. Control run}

In the control run, interactions between the surface hydrology and the atmosphere are effectively switched off. The model is forced with soil hydrological conditions based on daily soil moisture from the coupled run that has been passed through a 60-day low-pass filter to remove all variability on intraseasonal time scales. Hence, any intraseasonal signals that are found in the control run must be independent of any soil moisture feedbacks. The filter is applied globally to soil moisture at all four levels. Initial tests showed that in the Sahelian zone, wet season soil moisture values in the coupled run produced unrealistically low evaporation rates because of high values of $r_{\text {soil }}$. We wish to assess the sensitivity of the atmosphere about realistic values of $r_{\text {soil }}$. Thus, we increased top-level soil moisture in the control run by a factor of 2 between May and October across the region $\left(10^{\circ}-17.5^{\circ} \mathrm{N}\right)$, and the values of $r_{\text {soil }}$ were capped between 50 and $200 \mathrm{~s} \mathrm{~m}^{-1}$ over the domain $10^{\circ}-17.5^{\circ} \mathrm{N}, 15^{\circ} \mathrm{W}-41.25^{\circ} \mathrm{E}$. Level 2 soil moistures were also increased by a smaller factor (1.25) to prevent drainage.

\section{c. Perturbation run}

In the perturbation run, the ability of the model and the monsoon system to produce precipitation anomalies as a response to soil moisture perturbations is examined. Idealized soil moisture anomalies were imposed based on the lagged composites of soil moisture detected from satellite and the coupled run (Figs. 3 and 4). A 16-day cycle of evaporative resistance anomalies was created, ranging between values of $\pm 50 \mathrm{~s} \mathrm{~m}^{-1}$, and these were converted to top-level soil moisture anomalies. The repeating 16-day cycle of soil moisture anomalies was then added to the top-level daily soil moisture values (smaller magnitudes were added to level 2 soil moistures) in the control run during June-September. These anomalies in soil moisture are approximately $25 \%$ larger than those simulated in the coupled run (Fig. 5). These should achieve the desired result of a sensible heat flux response to the imposed forcing. The only difference between the control and perturbation runs are these imposed anomalies in soil moisture. A summary of the three runs is given in Table 1.

\section{Analysis of sensitivity experiments}

\section{a. Perturbation run analysis}

The atmospheric response to soil moisture forcing is examined in the perturbation run. The repeating 16-day cyclic soil moisture anomaly forcing was assumed to force a 16-day cyclic response in the model. This "forced" 
TABLE 1. Overview of the three model simulations and how they differ in terms of soil moisture.

\begin{tabular}{|c|c|}
\hline Name & Summary of soil moisture included \\
\hline Coupled & Fully interactive soil moisture. \\
\hline Control & $\begin{array}{l}\text { Forced with daily soil moisture that } \\
\text { has been passed through a 60-day } \\
\text { low-pass filter to remove any } \\
\text { variability on the intraseasonal time } \\
\text { scale. }\end{array}$ \\
\hline Perturbation & $\begin{array}{l}\text { As control but with an additional 16-day } \\
\text { cycle of idealized soil moisture } \\
\text { anomalies, based on observations. }\end{array}$ \\
\hline
\end{tabular}

response was diagnosed by averaging over the 16-day cycles in the model, using unfiltered data from the 122-day June-September seasons. The model was run for $23 \mathrm{yr}$; hence, each day in the model response cycle was an average of $23 \times 122 / 16=175$ independent days of data. The statistical significance of the values was found using a $t$ test (Wilks 1995) with 175 degrees of freedom.

Figure 6 presents the evolution over the 16-day cycle of key variables to the imposed soil moisture forcing pattern (shown in the left-hand column). Altering the moisture available for evaporation results in changes in the latent and sensible heat fluxes over the same region. Anomalously wet soil enhances latent heat at the expense of the sensible heat flux (Fig. 6b).

The soil moisture (and associated flux) anomalies also result in changes in the low-level atmospheric temperature. The decrease in sensible heating results in a cooler planetary boundary layer (PBL). At $925 \mathrm{hPa}$, negative temperature anomalies tend to occur at the same time as positive soil moisture anomalies (Fig. 6b). These temperature anomalies occur at slightly higher latitudes than the imposed soil anomalies. This is most likely due to advection by the mean state southwesterly winds over several days of anomalous heating. All of these features are consistent with Taylor (2008).

Over positive soil moisture anomalies, where there are negative low-level temperature anomalies, there is an increase in the mean sea level pressure (not shown). The anomalous low-level winds intensify in response to these pressure fields, resulting in anticyclonic circulation around the positive soil moisture (e.g., Fig. 6b, day -3). Likewise, a cyclonic circulation occurs in response to negative soil moisture, positive temperature anomalies, and negative pressure anomalies (e.g., Fig. 6b, day -7). Together, these anomalies describe the dynamics of surface heat lows and cold highs (Parker 2008). On day -7 (Fig. 6a), there are northeasterly anomalies to the west of the dry soil and southwesterly anomalies to the east with a cyclonic circulation over the dry soil. A region of wet soil is developing to the east of the dry soil. As the soil anomalies shift westward, so do the southerly wind anomalies. A region of dry soil anomalies has developed to the east of the wet soil by day 1 (Fig. 6a, day 1), with northeasterly wind anomalies between the wet and dry patches. By day 5 (Fig. 6a, day 5) there is only a small region of wet soil in the west and the dry soil has extended to the east.

The response of the atmosphere to soil moisture forcing in the model are in good qualitative agreement with observations (Taylor 2008). Quantitatively, the amplitude of surface heat flux differences in that study were in the range $20-25 \mathrm{~W} \mathrm{~m}^{-2}$ (Figs. 5 and 7; Taylor 2008), as compared to amplitudes here of approximately $15 \mathrm{~W} \mathrm{~m}^{-2}$. The weaker surface heat flux forcing (by approximately one-third) in the current study produces a weaker amplitude response in temperature (1.2 here compared to $2 \mathrm{~K}$ ) and wind (around 2 here compared to $3 \mathrm{~m} \mathrm{~s}^{-1}$ in the observational study) (Figs. 5 and 7; Taylor 2008). Through the use of a model, we are able to distinguish between cause and effect. The simulation demonstrates that anomalies in soil moisture feed back on the dynamics of the lower atmosphere. This could not be unambiguously diagnosed using observational analyses alone.

Anomalies in precipitation that occur as a forced response to the imposed soil moisture anomalies are shown in Fig. 6c. Compared to the dynamical fields, the forced precipitation anomalies are noisier and less coherent. Where significant precipitation anomalies occur, they are positively correlated with anomalous meridional winds. The percentage change in precipitation from the JuneSeptember climatology is also shown in Fig. 6c, and this indicates a much clearer effect of the soil moisture forcing on rainfall in the drier northern Sahel and Sahara. Anomalies in precipitation of $\pm 30 \%$ between $15^{\circ}$ and $20^{\circ} \mathrm{N}$ propagate westward, ahead of the soil moisture anomalies (Fig. 6a). Positive (negative) precipitation anomalies occur to the west of positive (negative) soil moisture anomalies. Anomalous northeasterly winds to the west of the dry patch on day 1 (Fig. 6c) coincide with the negative precipitation anomalies. Similarly, in other parts of the cycle (not shown), there are positive precipitation anomalies over regions where there is an enhanced southwesterly flow. An increase (decrease) in the southwesterly monsoon flow will advect more (less) moisture into the region. This suggests the precipitation anomalies are occurring because of an increase in the boundary layer moisture. The increased moisture is driven primarily by the large-scale circulation anomalies induced by soil moisture rather than the direct effect of increased surface evaporation.

The precipitation anomalies occurring in response to the imposed soil moisture anomalies (Fig. 6c) are a factor of 4 smaller than those occurring in the fully coupled run 
(a) Soil moisture

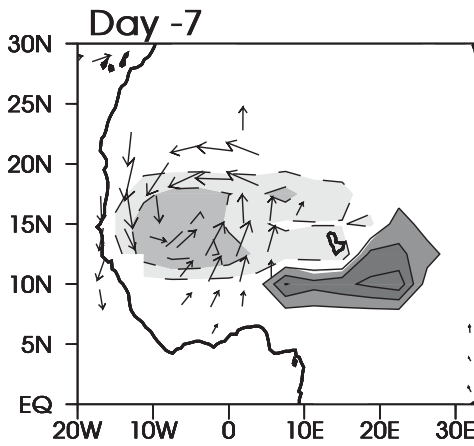

(b) $\mathrm{H}$; shading

T; contour (c) Precip fraction; shading anom; contour
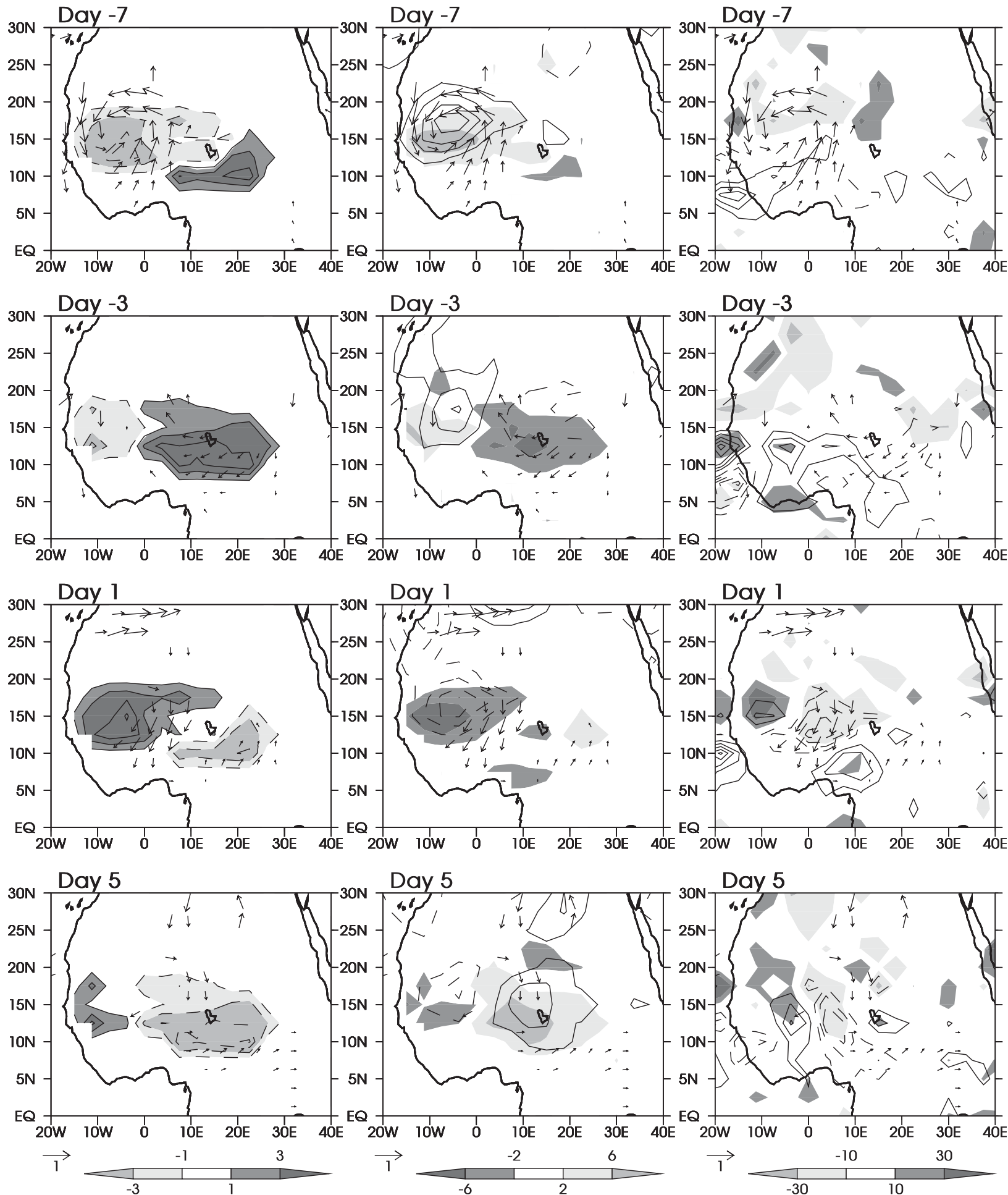

FIG. 6. Perturbation run response (unfiltered) to imposed soil moisture anomalies on days $-7,-3,1$, and 5 . Daily mean composites of (a) soil moisture $\left(\mathrm{kg} \mathrm{m}^{-2}\right)$, contours are plotted every $2 \mathrm{~kg} \mathrm{~m}^{-2}$, starting at $\pm 1 \mathrm{~kg} \mathrm{~m}^{-2}$; shading is shown by the legend; (b) sensible heat flux anomalies ( $\mathrm{W} \mathrm{m}^{-2}$, shading; shown by legend), temperature at $925 \mathrm{hPa}$ (contours; plotted every $0.2 \mathrm{~K}$ ); and (c) precipitation anomalies ( $\mathrm{mm} \mathrm{day}^{-1}$, contours) are plotted every $0.3 \mathrm{~mm}$ day ${ }^{-1}$. Change in precipitation (\%) from the climatological June-September precipitation is shaded, as shown by the legend. Low-level $(925 \mathrm{hPa})$ wind vector anomalies are plotted in all panels where either the $u$ or $v$ components are statistically significant at the $95 \%$ level. 


\section{Coupled run}

(a) Precipitation

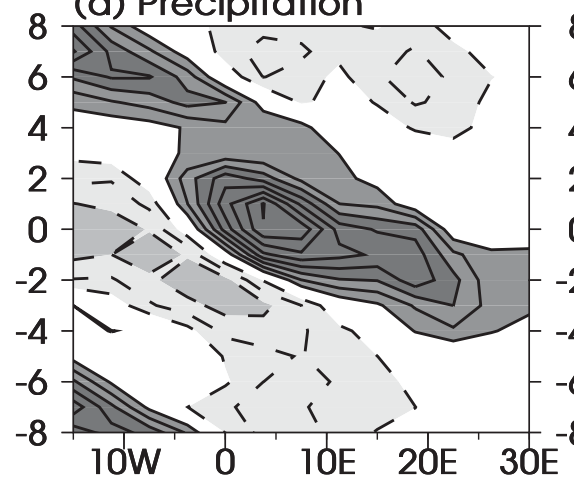

(b) Shortwave_in

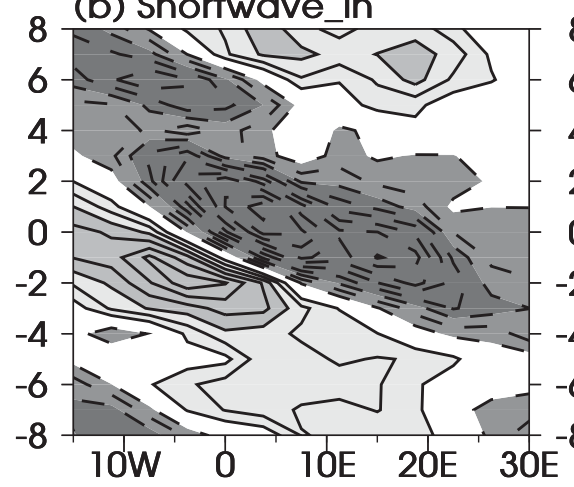

(c) Sensible heat

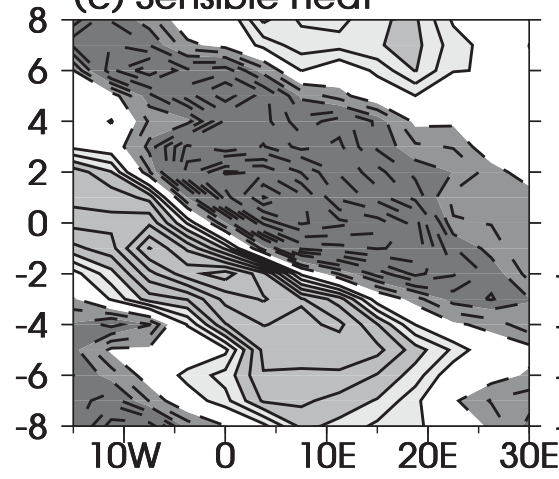

Control run

(a) Precipitation
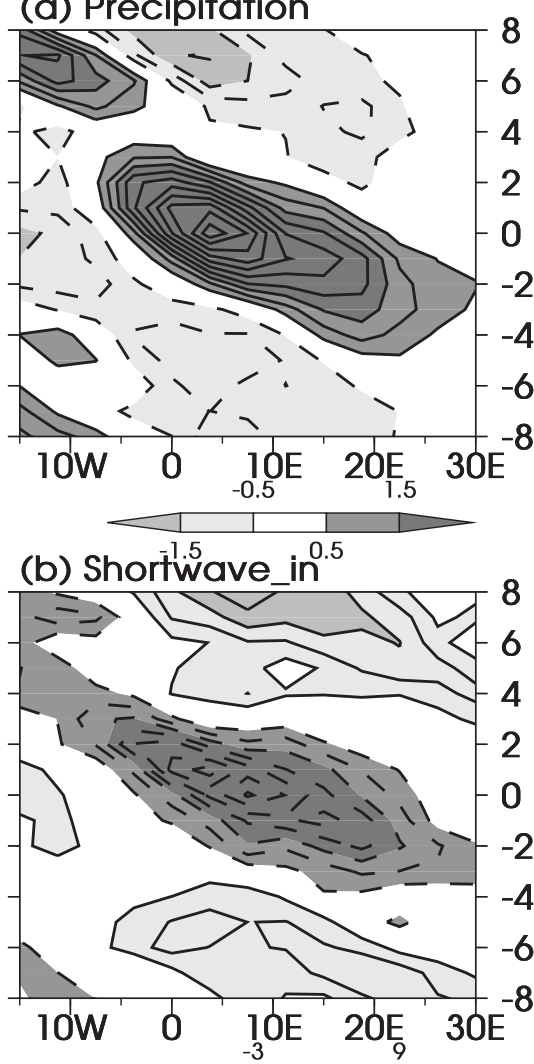

(c) Sensib̄le heat $^{3}$

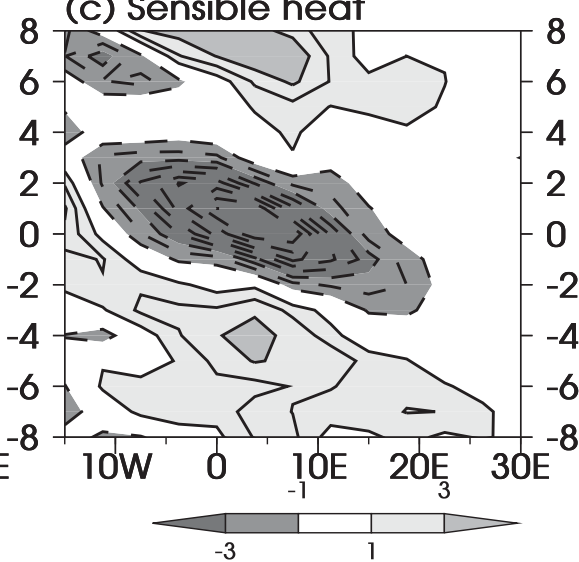

(a) Precipitation

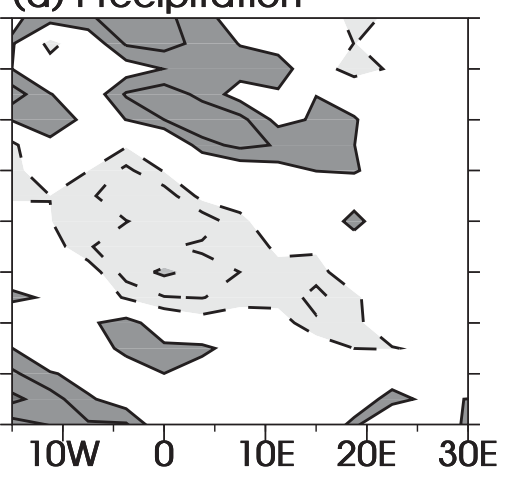

(b) Shortwave_in

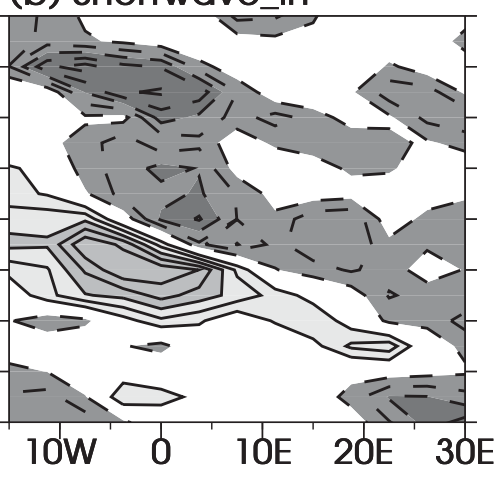

(c) Sensible heat

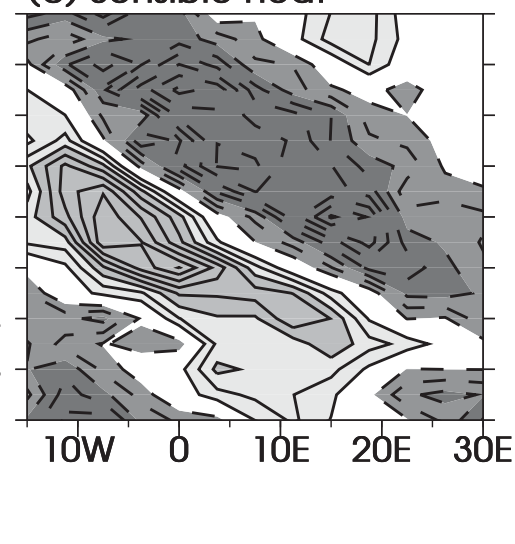

FIG. 7. Lagged Hovmöller diagrams of unfiltered data based on $\mathrm{PC} 1$ of precipitation, averaged between $10^{\circ}$ and $17.5^{\circ} \mathrm{N}$, from the coupled run, control run, and the coupled run minus the control run (difference). (a) Precipitation anomalies, contours are plotted every $0.5 \mathrm{~mm}$ day $^{-1}$. (b) Net incoming shortwave radiation; contours are plotted every $3 \mathrm{~W} \mathrm{~m}^{-2}$. (c) Sensible heat flux; contours are plotted every $1 \mathrm{~W} \mathrm{~m}^{-2}$.

when the analysis is based on soil moisture (Fig. 5). To investigate further the rainfall signal in the perturbation run, the EOF analysis described previously in section $3 \mathrm{~b}$ was repeated based on 10-25-day-filtered precipitation from the perturbation run. The amplitude of the precipitation signal is much larger when the analysis is based on precipitation rather than soil moisture. This suggests that the precipitation variability in the model is primarily independent of soil moisture. The control run will now be analyzed to investigate what happens when the 
link between surface hydrology and the atmosphere is effectively switched off.

\section{b. Control run analysis}

Given that there is no soil moisture variability in the control run (by construction), precipitation is chosen as the next most relevant variable on which to base the analysis. Hence, the EOF analysis based on 10-25-dayfiltered precipitation described above was repeated for the control run. Lagged composites were created based on when PC1 of 10-25-day-filtered precipitation was a maximum for each run independently. These are compared for the coupled and control runs using Hovmöller diagrams, averaged between $10^{\circ}$ and $17.5^{\circ} \mathrm{N}$ (Fig. 7).

A westward-propagating signal is clearly evident in the control run (Fig. 7a). Hence, to a first approximation, the westward-propagating mode is independent of soil moisture variability. Figures $7 \mathrm{~b}$ and $7 \mathrm{c}$ show the propagation of anomalies in surface insolation and sensible heat flux, respectively. These signals indicate that while the surface hydrological state remains constant in the control run, variations in cloud cover induce a sensible heat flux signal of approximately half the magnitude of the coupled run on day 0 . This anomalous surface heating can feed back on the temperature of the lower atmosphere in a manner similar to that seen in Fig. 6, albeit at lower amplitude.

Closer examination of Fig. 7a reveals that variability in precipitation is stronger in the control run in the central $\left(0^{\circ}-25^{\circ} \mathrm{E}\right)$ region but notably weaker in the west. This is confirmed in Fig. 8, which indicates markedly stronger precipitation variability west of $7.5^{\circ} \mathrm{W}$ and between $7.5^{\circ}$ and $15^{\circ} \mathrm{N}$ in the coupled run. This is most notable on days -7 and +5 , but it is a feature that is present throughout the 16-day sequence. The propagation of precipitation to the west is therefore not as coherent in the control run as in the previous experiments when interaction with soil moisture was permitted. This suggests that although the basic mode exists independently of soil moisture, the inclusion of land feedbacks can strengthen the propagation (Fig. 7).

Last, a notable feature in both simulations is the presence of a propagating vortex at $925 \mathrm{hPa}$ (Fig. 8) to the northwest of the precipitation anomalies $\left(20^{\circ}-25^{\circ} \mathrm{N}\right)$. Anticyclonic (cyclonic) anomalies occur to the northwest of suppressed (enhanced) precipitation. This vortex is consistent with that found in reanalysis data by Sultan et al. (2003), who highlighted its importance in the advection of moisture and enhanced precipitation.

This analysis suggests there is a westward-propagating signal in atmospheric variables on the intraseasonal scale independent of soil moisture. However, in the forced (perturbation) simulation, imposed variability in soil moisture also forces a precipitation response, albeit a weaker one. Hence, the implication is that the propagating mode becomes weakly phase locked to the soil moisture anomalies. The potential for feedback onto the soil moisture can be examined by calculating the phase relationship between soil moisture and rainfall in the perturbation run (Fig. 9). The day of peak precipitation relative to maximum soil moisture is found over the region $12.5^{\circ}-17.5^{\circ} \mathrm{N}, 7.5^{\circ} \mathrm{W}-15^{\circ} \mathrm{E}$ in each 16 -day cycle of imposed soil moisture in the perturbation run. The occurrence of peak precipitation relative to the soil moisture peak is shown in Fig. 9. There are 171 16-day cycles examined. If the precipitation was occurring independently of soil moisture, then an equal distribution of rainfall would be expected with a value of 171/16 for each lag. In fact, there is a strong preference for the peak in precipitation to lead the peak soil moisture by $0-4$ days; $58 \%$ of the maxima occur in this phase, which occupies only $31 \%$ of the time. The implication is that the atmospheric mode is coupled and phase locks with the imposed soil moisture forcing in the perturbation run.

It has been shown that although the response of the dry dynamics to soil moisture anomalies is consistent with observations, the precipitation response is not as clear. One possible reason for this is the phase locking discussed above, which results in interference between the westward-propagating mode in the control run and the partially phase-locked mode in the perturbation run. Also, the convection scheme in the model may play an important role in determining modeled sensitivity of precipitation to the land surface. The Global LandAtmosphere Coupling Experiment (GLACE; Guo et al. 2006) found weak coupling between evaporation and precipitation in HadAM3, the model used here. This model is also known to trigger convection too frequently (e.g., Lawrence and Slingo 2005), typically around midday on most days. This prevents the buildup of large instabilities, which in reality are only released intermittently in the Sahel.

\section{Conclusions}

Soil moisture anomalies have been found to have an important feedback on the simulated variability of the West African monsoon. Analysis of the model when the soil moisture was fully coupled with the atmosphere (as is done routinely within a GCM) showed a 15-day variability in soil moisture (Fig. 4) similar to that found in observational data (Fig. 3). The relationships between soil moisture and atmospheric variables at $925 \mathrm{hPa}$ were similar to an earlier study using data from atmospheric analyses (Taylor 2008). 
(a) Coupled run
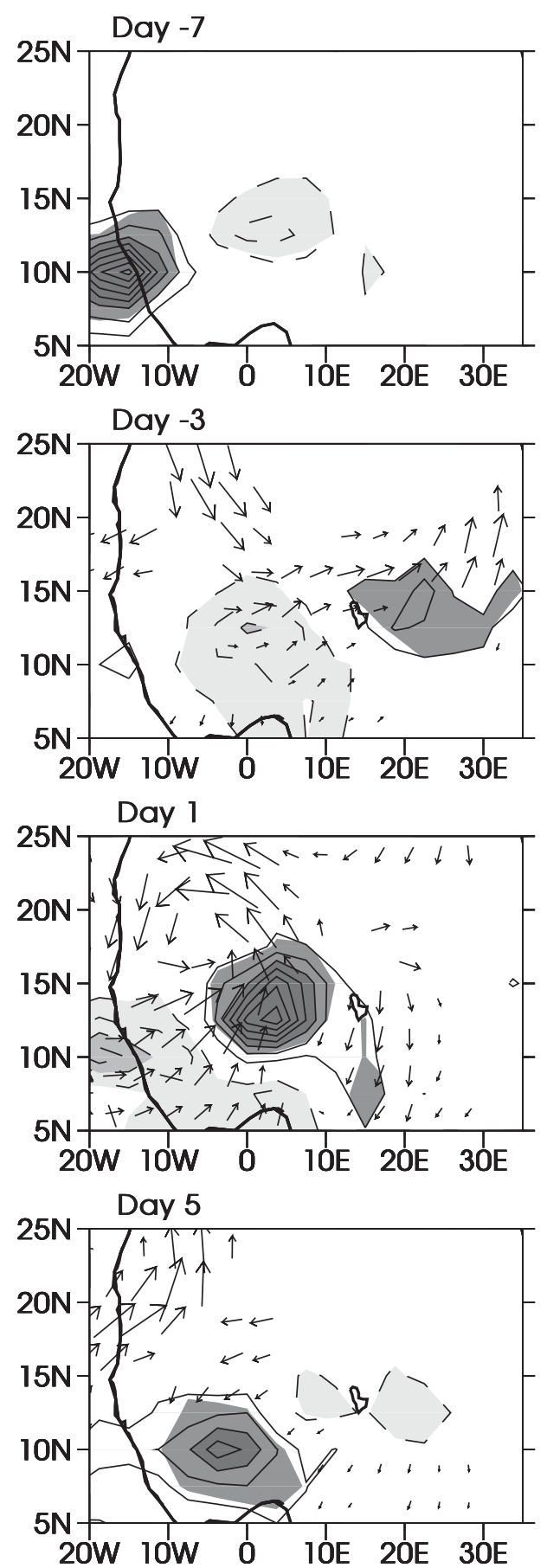

(b) Control run
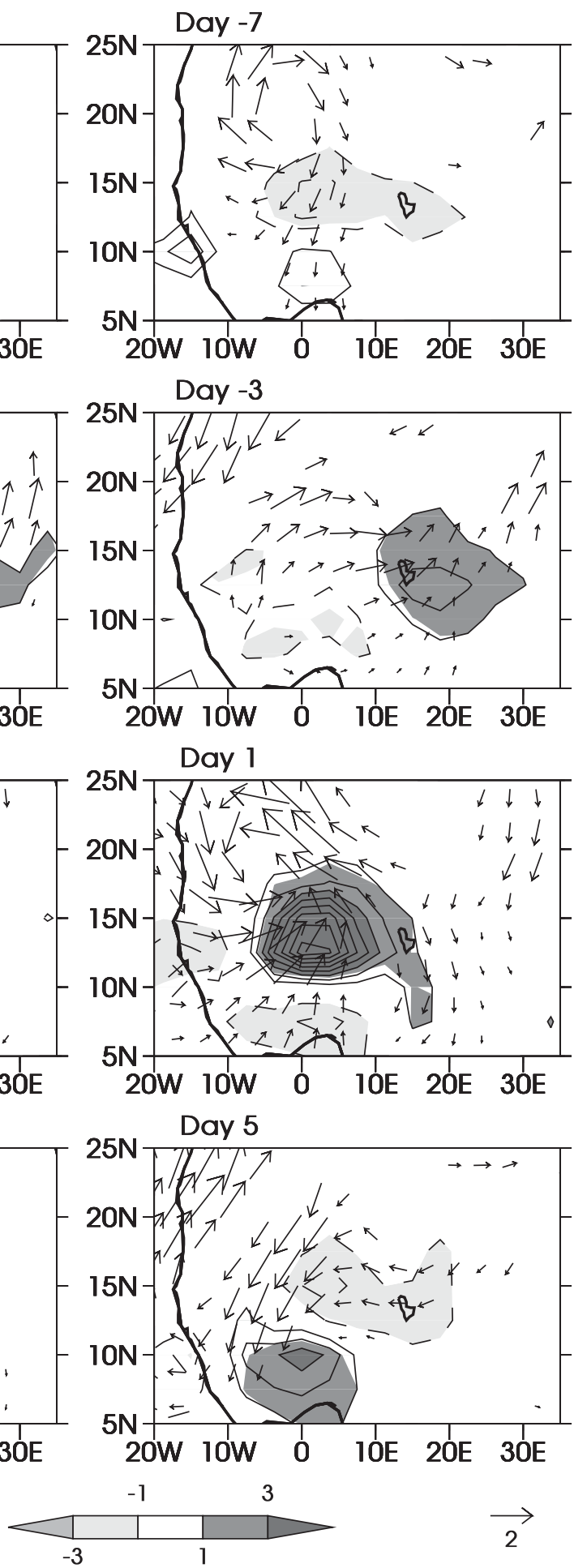

FIG. 8. Lagged composites on days -7 to 5 of unfiltered, modeled precipitation anomalies and 925-hPa wind vector anomalies from the (a) coupled and (b) control runs, based on PC1 of 10-25-dayfiltered precipitation, June-September of 1983-2005. Contour interval is $1 \mathrm{~mm} \mathrm{day}^{-1}$, and negative contours are dashed. Shading and vector scale are shown by the legends and show values significant at the $95 \%$ level. 


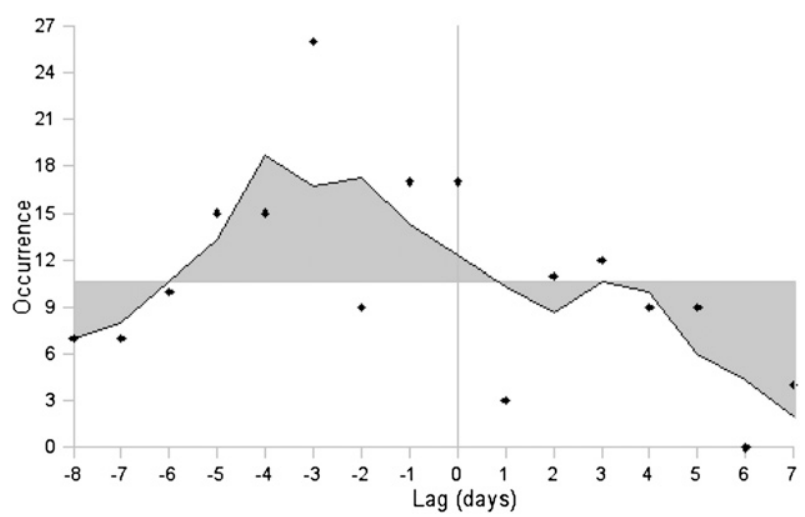

FIG. 9. Time series from lag -8 to lag 7 of the occurrence of the maximum in precipitation relative to the maximum in soil moisture in the perturbation run in a region $12.5^{\circ}-17.5^{\circ} \mathrm{N}, 7.5^{\circ} \mathrm{W}-15^{\circ} \mathrm{E}$. The dots represent the individual data points, while the line is the 3-day running mean. Regions above and below the value expected if no phase locking was occurring are shaded.

To examine the influence of soil moisture anomalies on the WAM, a cycle of soil moisture anomalies was produced based on the observed intraseasonal variability over West Africa. These soil moisture anomalies were applied as boundary conditions in the GCM (perturbation run). Analysis of the perturbation runs showed significant anomalies in several variables as a response to these soil moisture anomalies (Fig. 6). Soil moisture anomalies change the partition between the sensible and latent heat fluxes. As a result, anomalously wet soil results in negative low-level temperature anomalies and increased pressure. An anticyclonic circulation develops around the region of wet soil. The model confirms that soil moisture is important for the westward propagation of these circulation anomalies.

The link between soil moisture and temperature and winds is fairly direct; hence, the influence of soil moisture on the dry physics in the model is consistent with observational results (e.g., Taylor 2008). A weaker temperature and wind response is found in the model than in the observations; this is due to the lower magnitude of surface heat flux anomalies in the model. The link to precipitation is indirect and requires realistic sensitivity of the convection scheme to low-level moisture. However, the influence of soil moisture on precipitation is still evident in the model, with precipitation anomalies leading the soil moisture anomalies by a few days.

A sensitivity experiment (control run), in which soil moisture was prescribed with no 15-day variability, found that a westward-propagating precipitation mode existed independently of soil moisture. However, there were differences in magnitude in various features relative to the coupled run. These included differences in incoming shortwave radiation and sensible heat flux (Fig. 7). The existence of radiation-induced sensible heat anomalies will have a similar influence on the low-level atmosphere as soil moisture anomalies and hence may partly explain the presence of precipitation variability in the control run. Suppressing soil moisture variability had little effect on the amplitude of precipitation variability in the center of the continent; however, there was a notable weakening in the propagation of this variability toward the Atlantic Ocean. These differences are consistent with a soil moisture influence.

The presence of a westward-propagating signal in precipitation in both the coupled and control runs suggests that the variability in precipitation can exist as an atmospheric mode with radiative coupling to the land surface but independent of soil moisture. One possible explanation of this westward-propagating mode may be a convectively coupled equatorial Rossby wave (Janicot et al. 2009). These precipitation anomalies have an associated low-level vortex in circulation anomalies over the Sahel and Sahara. This variability in precipitation and low-level circulation becomes weakly phase locked to the imposed cycle of soil moisture anomalies in the forced response experiment. The precipitation anomalies are weaker than expected, partly because of the interference between the westward-propagating mode in the control run and the phase-locked mode in the perturbation run. The relative weakness of the precipitation response may also be due to known deficiencies in the model physics (Lawrence and Slingo 2005; Guo et al. 2006). Hence, this study highlights the need for further model improvements in correctly simulating the link between surface evaporation and precipitation.

It has been successfully demonstrated that variations in soil moisture influence the atmospheric variability of the WAM in a similar way to that found in observations (Taylor 2008), using assumptions about the influence of soil moisture on sensible heat flux, and hence feedback on the WAM. Intraseasonal variations in soil moisture feed back on the low-level circulation. Anomalies in low-level circulation are then thought to amplify rainfall variability.

Acknowledgments. We thank three anonymous reviewers for their valuable comments. SLL was funded by a NERC research studentship (Grant NER/S/J/2005/ 13614) as part of the AMMA-UK project. On the basis of a French initiative, AMMA was built by an international scientific group and is currently funded by a large number of agencies, especially those from France, the United Kingdom, the United States, and Africa. It has been the beneficiary of a major financial contribution from the European Community's Sixth Framework Programme. Detailed information on scientific coordination 
and funding is available on the AMMA international Web site (http://www.amma-international.org).

\section{REFERENCES}

Betts, A. K., and J. H. Ball, 1998: FIFE surface climate and siteaverage dataset (1987-89). J. Atmos. Sci., 55, 1091-1108.

Cullen, M. J. P., 1993: The unified forecast/climate model. Meteor. Mag., 122, 81-94.

Dharssi, I., P. L. Vidale, A. Verhoef, B. Macpherson, C. Jones, and M. Best, 2009: New soil physical properties implemented in the Unified Model at PS18. Met Office, Meteorology Research and Development Tech. Rep. 528, 35 pp.

Douville, H., 2002: Influence of soil moisture on the Asian and African monsoons. Part II: Interannual variability. J. Climate, 15, 701-720.

Essery, R. L. H., M. J. Best, and P. M. Cox, 2001: MOSES 2.2 technical documentation. Hadley Centre Tech. Note HCTN 30, $30 \mathrm{pp}$. [Available online at http://www.metoffice.gov.uk/ publications/HCTN/index.html.]

Folland, C. K., T. N. Palmer, and D. E. Parker, 1986: Sahel rainfall and worldwide sea temperatures, 1901-85. Nature, 320, 602-607.

Grodsky, S. A., and J. A. Carton, 2001: Coupled land/atmosphere interactions in the West African monsoon. Geophys. Res. Lett., 28, 1503-1506.

Gruhier, C., and Coauthors, 2010: Soil moisture active and passive microwave products: Intercomparison and evaluation over a Sahelian site. Hydrol. Earth Syst. Sci., 14, 141-156.

Guo, Z., and Coauthors, 2006: GLACE: The Global LandAtmosphere Coupling Experiment. Part II: Analysis. J. Hydrometeor., 7, 611-625.

Janicot, S., and B. Sultan, 2001: Intra-seasonal modulation of convection in the West African monsoon. Geophys. Res. Lett., 28, 523-526.

_ A. Harzallah, B. Fontaine, and V. Moron, 1998: West African monsoon dynamics and eastern equatorial Atlantic and Pacific SST anomalies (1970-88). J. Climate, 11, 1874-1882.

- , F. Mounier, N. M. J. Hall, S. Leroux, B. Sultan, and G. N. Kiladis, 2009: The dynamics of the West African monsoon. Part IV: Analysis of 25-90-day variability of convection and the role of the Indian monsoon. J. Climate, 22, 1541-1565.

Koster, R. D., and Coauthors, 2004: Regions of strong coupling between soil moisture and precipitation. Science, 305, 1138-1140.

Lavender, S. L., and A. J. Matthews, 2009: Response of the West African monsoon to the Madden-Julian oscillation. J. Climate, 22, 4097-4116.
Lawrence, D. M., and J. M. Slingo, 2005: Weak land-atmosphere coupling strength in HadAM3: The role of soil moisture variability. J. Hydrometeor., 6, 670-680.

Lebel, T., F. Delclaux, L. Le Barbe, and J. Polcher, 2000: From GCM scales to hydrological scales: Rainfall variability in West Africa. Stochastic Environ. Res. Risk Assess., 14, 275-295.

Livezey, R. E., and W. Y. Chen, 1983: Statistical field significance and its determination by Monte Carlo techniques. Mon. Wea. Rev., 111, 46-59.

Matthews, A. J., 2004: Intraseasonal variability over tropical Africa during northern summer. J. Climate, 17, 2427-2440.

Mounier, F., and S. Janicot, 2004: Evidence of two independent modes of convection at intraseasonal timescale in the West African summer monsoon. Geophys. Res. Lett., 31, L16116, doi:10.1029/2004GL020665.

- - — , and G. N. Kiladis, 2008: The West African monsoon dynamics. Part III: The quasi-biweekly zonal dipole. J. Climate, 21, 1911-1928.

North, G. R., T. L. Bell, R. F. Cahalan, and F. J. Moeng, 1982: Sampling errors in the estimation of empirical orthogonal functions. Mon. Wea. Rev., 110, 699-706.

Owe, M., R. A. M. de Jeu, and T. R. H. Holmes, 2008: Multisensor historical climatology of satellite-derived global land surface moisture. J. Geophys. Res., 113, F01002, doi:10.1029/ 2007JF000769.

Parker, D. J., 2008: A simple model of coupled synoptic waves in the land surface and atmosphere of the northern Sahel. Quart. J. Roy. Meteor. Soc., 134, 2173-2184.

Reynolds, R. W., N. A. Rayner, T. M. Smith, D. C. Stokes, and W. Wang, 2002: An improved in situ satellite SST analysis for climate. J. Climate, 15, 1609-1625.

Rowell, D. P., C. K. Folland, K. Maskell, and M. N. Ward, 1995: Variability of summer rainfall over tropical North Africa (1906-92): Observations and modelling. Quart. J. Roy. Meteor. Soc., 121, 669-704.

Sultan, B., S. Janicot, and A. Diedhiou, 2003: The West African monsoon dynamics. Part I: Documentation of intraseasonal variability. J. Climate, 16, 3389-3406.

Taylor, C. M., 2008: Intraseasonal land-atmosphere coupling in the West African monsoon. J. Climate, 21, 6636-6648.

_, F. Saïd, and T. Lebel, 1997: Interactions between the land surface and mesoscale rainfall variability during HAPEXSahel. Mon. Wea. Rev., 125, 2211-2227.

Wilks, D. S., 1995: Statistical Methods in the Atmospheric Sciences: An Introduction. Academic Press, 467 pp. 